Article

\title{
Mushrooming Communities: A Field Guide to Mycology in the Community Forests of Portugal
}

\author{
Rita Serra ${ }^{1, *}$, Eugénia Rodrigues ${ }^{2}$ and Raúl García-Barrios ${ }^{3}$ \\ 1 Centre for Social Studies, University of Coimbra, Colégio de S. Jerónimo, Largo D. Dinis, Apartado 3087, \\ 3000-995 Coimbra, Portugal \\ 2 Baldios dos Lugares da Extinta Freguesia de Vilarinho, Lousã, Rua Sr. das Preces 8, 3200-407 Vilarinho LSA, \\ Portugal; eugenia_joao@hotmail.com \\ 3 Regional Centre of Multidisciplinary Research, National Autonomous University of Mexico, \\ Av. Universidad s/n, Circuito 2, Col. Chamilpa, Ciudad Universitaria de la UAEM, 62210 Cuernavaca, \\ Morelos; rgarciab@servidor.unam.mx \\ * Correspondence: ritaserra@ces.uc.pt; Tel.: +351-239-855570
}

Academic Editor: Marc A. Rosen

Received: 20 April 2017; Accepted: 23 May 2017; Published: 1 June 2017

\begin{abstract}
Forest community connections are crucial to ensure forest stewardship and sustainability. We explored the potential of mushrooming to enable such connections in contexts where these connections have been historically broken, alienating local people from forests. Taking the case of the recent devolution of a community forest (baldios) in central Portugal to the local population, we present a five-year pilot project to rework mycology from a mushroom-centered approach to a mushroom-in-baldios approach. Mushrooms were used as an entry-point to connect the forest ecology with the challenges of governance and community building. The devised activities provided an opportunity for people inside and outside the local community to adventure into the woods and find out more about their socio-ecological history, develop communal and convivial relationships and engage in the responsible gathering of wild mushrooms. However, the hosting of mushroomers to know, value and engage with the community forest recovery has constantly worked against the enclosure of mushrooms to provide marketable forms of leisure. The outcome of these activities depends on the relationships established between mushrooms, mycologists, local administrators, commoners and poachers, all operating within a framework that favors the eradication of resources instead of long-term relationships that sustain places.
\end{abstract}

Keywords: common lands; baldios; wild mushrooms; non-timber forest products; Portugal; community; community forestry; forest governance

\section{Introduction}

Mushrooming in Portugal is a naturalistic tradition with the potential to engage its practitioners in a responsible relationship with the environment, especially forests. As the mycelia of mushrooms connect the trees with dead matter and lively microbes [1], their fruiting bodies provide the ground for people to experience nature, value it and intimately connect it to human sociability [2]. Such valuation of nature and the diverse creatures inhabiting the woods is essential to connect people to the stewardship of forests [3], especially when such connections have been broken resulting in the eradication of forest goods, socio-environmental degradation and, occasionally, land abandonment [4].

Mushrooming is a recreational practice mostly undertaken by city dwellers that seek refuge from overwhelming and emotionally exhausting lives, in search of communal ways to share the pleasures and wonders of knowing about mushroom's secrets, eating wild delicacies, and being together in nature. This definition of mushrooming corresponds broadly to mushroom picking by hobbyists [2], 
which may differ from traditional forms of mushroom collection by rural populations. Wild mushrooms are culturally understood by many persons as natural gifts [5], and together with other non-timber forest products (NTFPs) are gathered informally by a wide range of people in unenclosed forests, regardless of the land ownership regimes [6]. However, the official attitudes towards this practice vary substantially within and between countries. In Europe, in some northern European countries the gathering of wild mushrooms for recreational purposes constitutes everyman's right [7]; in some eastern European countries the practice may be against formal rules but informally tolerated [8]; and in southern European countries this right is exclusively entitled to the forest owner [9]. Mushroomers face increasing regulation due to the widespread overpicking of commercially-valued species that can be particularly violent and destructive due to fierce competition from outside capitalist, state and moral forms of control [5]. Simultaneously, they struggle against forest simplification and degradation, which fuel the continuous alienation of people from forest spaces. Although mushroomers may educate the general public about the importance of fungi and press for respectful ways of protecting, using and being in nature, they do not own or manage of the forests. As such, their capacities to engage directly in the stewardship of the fungi and the forests they visit are limited.

Community involvement in forestry has many times been presented as a panacea to overcome the past and ongoing mistakes of forest models of development, which alienate people and fail to benefit the local populations. This is the case of community forestry, which can enhance local control over common spaces under multiple arrangements and institutional regimes historically established [10]. As there is more local control, there are higher expectations that forests can finally provide for multiple purposes such as quality jobs and a fair distribution of the forest revenues. A central aspect for the success of community-based initiatives is its ability to create sustainable connections among the people and the place they live in [11]. Although challenging, local governance of common spaces can engage local populations in their stewardship, and thus potentially at least promote sustainable practices.

The pressure for alternative forms of forestry places NTFPs as the best way to reconcile sustainable forestry with rural development. Local communities are thus encouraged to commercially explore these non-timber resources to generate sustainable economies. However, when it comes to wild mushrooms, our critique is twofold. On the one hand, commercialization of NTFPs disregards the reality that informal practices of gathering wild species are integral to people's lives [6]. On the other hand, the fruiting patterns of wild species are unpredictable with extreme variations over space and time. Thus, the commercial viability of wild mushrooms frequently depends more upon mobile harvesters than upon local residents. In fact, mobile harvesters might come to be the best resource stewards, as they have a deeper knowledge on the variability of mushroom availability across larger areas and may develop a sense of place overtime [12].

In the Iberian Peninsula, landowners are trying to overcome these problems. In Galicia in northwestern Spain, some local communities are using mycorrhization techniques to enhance fungal productivity and are closing access to outsiders [13]. In some other provinces of Spain, forest administrations are undertaking pilot projects to sell permits to harvesters, which entitle them to pick wild edible mushrooms [9]. The latter aims to satisfy the personal recreational needs to gather wild mushroom species through a market form. However, it remains to be seen if the need for sociality that emerges from sharing the pleasure of mushroom gathering with an empathetic community can be fully satisfied in this format.

In Portugal, we set out to explore a different possibility to promote the stewardship of fungi and community forests. We asked the question, to what extent can mushroomers and local communities mutually reinforce each other to strength the connection between people and forests, supporting woodland restoration and the responsible gathering of wild mushrooms, without shutting the access to outsiders? Theoretically, this question has deep roots on how the relationship between humans and nature can result in the responsible use and stewardship of the environment versus its eradication and abuse, which will be detailed elsewhere. For the purpose of this paper, we use a heuristic for two different pathways towards the responsible engagement of people with nature: The mushroomer way 
and the commoner way. Both ways have the reverse direction, which prevents respectful social and ecological relationships from coming into being. We seek to understand how these ways interfere with each other and if they can result in meaningful connections between people and forests.

The mushroomer way is expressed in the ethical code adopted by mycological associations and expressed in their field guides and field trips. Such code may be summarized in one principle: Respect the ecological integrity of nature. Intimate knowledge between the mushroom wanderer and the space develops through multiple visits that allow finding the "mushroom hot spots" to which they can return every year. Mushrooming is more interested in observing species diversity and ecologic relationships, and of course on the pleasure of finding a meal in the woods, than in making a profit out of wild mushrooms. Voluntary mycological organizations provide for these leisure activities and facilitate the access to global scientific and amateur knowledge on the species biology, taxonomy and ecology, by creating opportunities for mushroomers to meet with experts and collectively experience nature and mushrooms as meaningful others [2]. Mushroomers may also, but not necessarily, be interested in understanding the habits of local owners in order to expand their knowledge of mushrooms for food, medicine and spirituality [14]. When it happens, mushrooming becomes a practice that enhances the ability to establish substantive relationships [15] with human and non-human species that are socially meaningful and shape the moral character. In its reverse, mushroomers may be interested in nature but not in people, and their way may become an expert-lay knowledge divide [16] and a source of unattached or even disrespectful attitudes towards local peoples and their efforts to build a livelihood.

The commoner way searches to ensure the provision of a community through the sustainable use of natural resources. Typically, its strength is not the provision of leisure or ecological integrity, but the satisfaction of basic needs and the production of public goods. The community of users shares rights and responsibilities towards the maintenance of the common resources. Collective rights to access and use are regulated through historical sets of norms entitling the community to exclude outsiders and those who do not follow the rules [17]. It is expected that the enactment of social practices to produce and reproduce natural public goods can be mutually constitutive of its practitioners, and hence radicate people in place such that their flourishing becomes interdependent with the nature that provides them [15]. Thus, responsibility towards such common goods becomes a duty of the commoners. In the reverse, commoners can limit their responsibilities to those cycles of nature and wild species that have direct use value for them, and disrespect ecological integrity in the case they decide to go for land improvement, species domestication, and construction and maintenance of common infrastructures. In addition, they may exclude non-commoners to safeguard the preservation of the common goods and their sustainable access. Thus, they may reject including new members or reforming their practices (a tendency that may exacerbate when an elite of commoners captures the common lands [18]). In Portugal, open access to common lands is widespread, and access rights have been traditionally attributed to all the residents living in a locality such as a village or town. Thus, recent immigrants can collect diverse goods such as fodder and fuel, and also wild foods as mushrooms, and such openness is easily extended to visitors. Commoners expecting new members or wanderers to contradict the way they manage the land and its resources may put into question such rights.

The aforementioned pathways require a meeting ground for mushroomers and commoners to experience wild mushrooms and all the invisible practices that sustain community forests and their ecological integrity. This meeting ground is not readily available and must be provided as a device that enables people with distinct material, cognitive and moral resources to understand, value and place in common what they have just experienced. As will be explained in the next sections, the past encounters with experts and city dwellers have been harmful and deprecatory for the commoners. Thus, we aim to re-work devices for the commoners to meet with the outsiders as stewards that hold the responsibility over the forest and aim to promote responsible and respectful relationships between people and nature. 
We present here a five-year pilot project to understand the potential of mushrooming via the stewardship of common lands in Portugal (named baldios), along with the recovery of a communal forest. The paper is organized in five sections. In the first section, we provide the methods. In Section 2, we outline the context for community forests and access to wild mushrooms in Portugal. In Section 3, we characterize the setting where the research activities took place. In Section 4, we describe the re-working of the mycological activities and the devices designed in the context of community forestry. In Section 5, we end by discussing the larger implications for mycology regarding its potential to engage people in the active stewardship and common governance of the land.

\section{Methods}

This research resulted from a collaboration protocol between the Centre for Social Studies of the University of Coimbra and the Community of Commoners from the baldios located at Vilarinho, Lousã, with the expertise and guidance in academia-community relationships of the Regional Center for Multidisciplinary Research of the National Autonomous University of Mexico. The protocol aims at the co-production of knowledge for the governance of the common lands, and one of the lines of work was the creation of devices to facilitate the connection of commoners with the common lands. The authors actively contributed to this institutional partnership and have been working in close collaboration with the local administrators to design, prepare, implement and evaluate the activities. The governance of wild mushrooms was one of the first concerns to be addressed. This was possible by combining the skills of the leading author, a trained biologist with expertise in mycology and mushrooming, with the competences of the second author who was responsible for technical forest management of the baldios.

Fieldwork was conducted over five years and included the document analysis and in-depth interviews of key forest actors and technicians in the central state forest services, non-governmental organizations for the responsible forest management, firefighters' associations, forest owner cooperatives and associations, lawyers, territorial planners, key scientists and opinion-makers to examine and situate community forestry in the context of Portugal. The first author also participated in diverse gathering forays across the country organized by mycological and forest associations.

Fieldwork at Vilarinho included the participation in regular meetings with the local administrators, technicians and forest workers; field visits; informal gatherings; local festivities and commoners' assemblies; and the compilation of detailed field notes. The authors were in constant communication with the local administrators during the design, preparation, implementation and evaluation of the mycological activities. Forays were conducted annually, and mushroom training courses were conducted biannually. Focus groups were conducted with the participants of the training courses. The presentation of results and key reflections were informed by the experience acquired through these practices in light of and in contrast to the heuristic presented in the introduction.

\section{Regimes of Forest Ownership and Mushroom Access in Portugal}

Portugal has $35 \%$ of its mainland territory covered by forests. Of these, $3 \%$ are under public ownership, the lowest percentage in Europe [19] and second lowest in the world [20]. Although this can be singled out as a problem for connecting forest management with the public good, it obscures the actual role of the central state in forest management and nature conservation [21]. In particular, it obscures how the promotion of policies towards forest monocultures can prevent sustainable multifunctional forests from coming into being, as well as alternative solutions to provide public goods, namely through small owner collectives and community forests.

Portugal has 400,000 small forest owners [22] that together hold $81 \%$ of the forest area, but most of these individually have properties under 4 ha $[23,24]$. Local communities hold $10 \%$ of the forests mainly in mountain areas [25]. Industrial owners hold the remaining $6 \%$ of the lands [23], although they are responsible for the management of a much wider area by holding the lands rented by non-industrial private and community owners. This is especially the case of eucalyptus, the main tree species in the 
country, where $28 \%$ of the plantations are managed by the paper and pulp industry [22]. However, all these are estimates as forest owners are not legally required to register their lands and, thus, these numbers do not figure in the National Forest Inventory.

Natural forests and woodlands are residual in the country, and following eucalyptus (Eucalyptus globulus), the most predominant species are cork oak (Quercus suber) and maritime pine (Pinus pinaster) [26]. Apart from cork oak montados, which are ancient agroforests still found in latifundiary regimes below the Tagus river [27], most forests result from pine and eucalyptus plantations that disrupted and replaced the complex agro-silvo-pastoral systems that existed in central and north Portugal that connected life in the villages with the mountain areas [28,29]. Traditional agriculture was produced in an intensive polycultural regime that was made possible through the access to the common lands that were true multifunctional spaces and provided pasture, natural fertilizers (brushland), firewood and a diversity of natural products such as mushrooms, berries, medicinal plants, construction materials, and water, among others. Agriculture was practiced in small parcels of land by families, and thus appeared what at first seems like a paradox: A minifundiary regime of agriculture combined with a communitarian access to the land.

Portugal suffered a significant forest transition resulting from state forest policies, particularly from the 1930s onwards [21,30]. Rural areas suffered a severe depopulation due to peasant migrations into the cities, the colonies and later on, to European countries short of labor in the post-war period. Family agriculture was truly at subsistence level and offered no prospects of increasing the production to live a better life. State forest policies aggravated this condition by submitting the common lands to the forest regime, which implied the afforestation and control of these lands by the central state forest services for the purpose of timber and taxes, impeding traditional usufruct rights [31]. This was often a process imposed from above with limited or no participation of the rural populations and occasionally with violence. However, while the forced afforestation of the common lands was disastrous, the afforestation by initiative of the owners and local communities flourished. What was at stake in afforestation was the potential for local communities to keep the control over their local lands. For private owners, afforestation was a way to secure access to forest goods that were otherwise lost by the submission to the state forest regime and an alternative non-agricultural use that allowed them to keep land and the forests as a reserve, as some put it, similar to having "money in the bank" [32,33]. In the 1930s and 1940s, afforestation was made with pine trees, which were traditionally cultivated in extensive regimes and the decision to cut was more related to family needs than with technical criteria. A curious trait that emerged in the planted pine forests, through private initiative, was that the landowners allowed or at least tolerated the picking of mushrooms, berries and pinecones by local residents and mushroomers as long as the harvest was not for profit. Thus, although these forests were private, public access was allowed for certain practices that did not collide with the trees well-being. This freedom of access also resulted from the practical difficulties of monitoring the entry of trespassers into private forests, which would come at the cost of the landowners having to fence their properties.

Between the 1990s and 2000s, there was a boom of mycological associations in Portugal [34]. Initially, these were an expression of the naturalistic interests of urban dwellers, who wanted to connect with nature and find out more about the potential of wild species for food and health. The growth of interest was supported by amateur mycological associations in Spain, which attracted a considerable number of mushroom enthusiasts. However, the situation started to change as products that traditionally had primarily a personal-use value, such as pinecones and mushrooms, acquired market value. In Portugal, these market value products belong to the landowner. Conflicts between those gathering products for market and the forest owners started to emerge, as forest owners aimed to diversify and manage their forests in a multifunctional perspective, as they also were interested in commercializing non-wooded forest products. More effort was put in by the landowners to prevent trespassers, and a general outrage against irresponsible wild mushrooms harvesters emerged, at the sight of scavenged forest soils by harvesters that picked everything in their way to sell to the commercial market. Thus, mycological walks became more restricted to areas of public access. However, they were 
also restricted in conservation areas: Although people may roam the forests, they were prohibited from harvesting any species along the way.

Increasingly, private forests are becoming more hostile to mushroomers. On one hand, pine trees in Portugal are facing severe pest attacks and being replaced by other crops in intensive regimes [26]. Multifunctional forest management requires a considerable area to be economically sustainable, and the policies to incentivize the collective management of forest areas and the associativism of the small forest owners that planted "minifundiary forests" seem to result in an active failure [32,35]. On the other hand, fast growing crops, in particular Eucalyptus plantations, have been actively promoted by the state since the 1980s to support the national pulp and paper industry, first through the forest services and the public pulp and paper company, and latter through financial incentives to private forest owners [21]. In unfavorable settings for collective action, the plantation of eucalyptus appears to individual forest owners as the rational choice for a fast profit [32]. Although this may be misleading (the cost of a plantation may in fact surpass the income from wood for a number of reasons, which may lead to its abandonment and the emergence of "zombie forests" - undead eucalyptus stands of thin burned trees sprouting from the trunk [36] especially in areas with recurrent fires), eucalyptus plantations have become the dominant forest landscape. Eucalyptus landscapes managed for profit or abandoned have limited scenic value and are not good places for family hiking and recreation. Unless there are conditions that allow them to age and mature, through natural regeneration of the indigenous trees, flora, fauna and mycorrhizal fungi, they remain degraded spaces with reduced biodiversity, and suffer the pressure from unsustainable and damaging activities such as motorized sports.

As said previously, although the state only owns 3\% of the land, it has an important role in forest policies actively favoring massive eucalyptus plantations. However, the state's role as forest administrator is frequently overlooked. Actually, the forest services co-administers $60 \%$ of the common lands [4], which corresponds to 412,143 ha [25]. This is the direct result from the devolution policies of the common lands, which took place in the framework that followed the "carnation revolution" of 25 April 1974. The newly democratic state proposed a form of organization to devolve the lands to the rightful community owners, and provided the opportunity for them to choose either to manage their forests without intervention of the State Forest Services, or in co-administration. Although the original setting for the devolution was to include baldios in the agrarian reform, shortly afterwards the process was halted and the state never provided the local communities with capacity needed to directly manage their forests. In practice, co-administration corresponded to the forest administration by the state, who provided a share of the forest revenues to local communities.

State forest management is becoming progressively unsustainable, due to a combination of factors. The degradation of the forest services since the 1980s due to new public management policies and the neoliberalization of the state severely eroded their capacities to directly manage the forests, which resulted finally in the state agencies delegating responsibilities to the private sector [21]. Simultaneously, the Forest Services could never overcome the loss of their authority over the common lands and enter into a mindset more favorable to the participatory and collaborative approaches with local communities [30]. The proliferation of fires, invasive species, pests and pathogens in the areas under their control exposed their weaknesses in managing new risks resulting in degraded spaces badly in need of environmental recovery. Of these issues, forest fires were particularly relevant for the local populations, as it affected them directly through the loss of property, health and their very lives [37]. The situation of the large fires in 2003 and 2005 lead to a shift in the national fire policy, forcing the forest services to collaborate with private owners and local communities in fire prevention for the first time, through a national program of forest fire prevention and specialized fire brigades. This necessity of collaboration inadvertently helped build the capacity of local populations for forest management, creating an opportunity to engage them in forest administration.

While the administrators of the common lands became progressively more aware of the forest issues, the local populations were unaware of their own collective rights and responsibilities. With the loss of traditional practices and uses and the long-term state administration of forests, the inhabitants 
typically consider forest management out of their control. In fact, baldios in the popular imagination and lexicon remain as synonym of wastelands, empty abandoned spaces, environmentally degraded and which no one cares about. Thus, the emergence of community forestry faced at least two gigantic challenges: (1) the full devolution to the local communities of the forests in the common lands; and (2) the necessity of creating a connection between forest and its local inhabitants. Here we detail the potential of mushrooms to provide a favorable setting precisely for such connection, and will make these challenges more explicit in the description of the case study.

\section{The Case of the Community of Commoners from the Baldios of the Places of the Extinguished Parish of Vilarinho, Lousã}

Vilarinho is located in the central interior of Portugal, in the Serra da Lousã mountain range and the study area is a part of the municipal territory of Lousã [38]. The very name of the community reflects the policies to extinguish local forms of organization. The parish is the lowest level of territorial administration in Portugal and was a contested place when local identities were formed. With the progressive loss of communitarian life at the places, the parish became a common denominator for the inhabitants within a geographical area. However, in 2013, the administrative reorganization of the parishes territory extinguished $27 \%$ of the parishes, some of which, including Vilarinho, are still struggling to regain their lost status.

In Portugal, the commoners' rights to common lands are pending on the resident status of a place with traditional usufructary rights [39]. What is significant to determining a resident's status has differed over the years, but typically consists of the citizens being able to vote in local elections, and who live or work in the locality most of the time. In Vilarinho, the commoner status is firmly associated with the voters of the extinguished parish [40]. There are over 3000 people with this commoner status due to the proximity of the village to the Municipality of Lousã, and while most of them are urban dwellers, some are also engaged in agro-silvo-pastoral activities.

The constitution of the local power of the Municipality historically affected the surrounding villages, parishes and places. The socio-economic and political life of Vilarinho is deeply dependent on Lousã, and although its inhabitants may imagine themselves as descendants from past mountain villagers, they identify mostly with town dwellers, as the attitude towards village people was and is still deprecatory today [31].

Most of the Vilarinho households are located below $250 \mathrm{~m}$ altitude. The common lands comprise close to 1000 ha of mountain territory with a maximum altitude of $1000 \mathrm{~m}$, which were submitted to the forest regime in the 1940s. The forest services planted trees unfamiliar to the local populations, such as Pseudotsuga menziesii (Douglas fir) and Chamaecyparis lawsoniana (Lawson cypress), as well as five species of pine trees. Prior to the state afforestation, commoners planted chestnuts (Castanea sativa) for their personal use, some of which are still living at more than 100 years old [39]. Traditional land uses were discontinued by the majority of the population, as agricultural activities nowadays consume commercial fertilizers and there are no herds in the area. There is a large consumption of firewood for heating, but this is ensured through commercial circuits by local providers. Deadfall is not typically harvested by the local populations due to the physical effort required.

Current uses of the common lands include apiculture, hunting, leisure activities, and mountain and radical sports (such as mountain trails and paragliding). Mountain territories in general can also support diverse uses outside the scope of agro-silvo-pastoral and related activities. In Vilarinho, the most economically relevant are the concession to a wind park at the higher altitude areas and infrastructures, namely an aerodrome and research facilities related to forest fires.

After the devolution, the forests of the baldios of Vilarinho continued to be co-administered by the State. However, conflicts between the local managing council and the Regional Forest Services emerged due to the authoritarian culture of the Services that materialized in everyday disputes such as the full prohibition of cutting and removing fallen down trees. The managing council of the baldios tried to gain a better capacity for forest management, and implemented the fire brigades program 
by hiring a team of forest workers. The council also sought technical advice from the regional office of the National Federation of the Common Lands and made significant investments in machinery, partially made possible through the concessions that provided the village with incomes. Since 2006, they have tried to put an end to the co-administration regime, but the state has denied their requests. With the support of a lawyer, the community of commoners finally saw their claim recognized by the Court of Law in 2012 [38]. They quickly hired on a full-time basis the forest engineer that previously worked with them. Their need for professional support came not only from the increased amount of work due to the autonomous forest management, but also from the failure of the regional office of the National Federation of the Common Lands to ensure technical support to its associates.

The forest engineer envisioned a multifunctional management plan for the common land forests, consisting of a productive forest capable of addressing the multiple needs of the commoners and the public. This vision was fully in line with the will of the local council of baldios to support local jobs, produce revenues and goods for the forthcoming generations. However, they had to overcome significant socio-ecological challenges.

As a start, the local people involved in the common lands administration were mostly elderly and now-retired individuals. Many of these people experienced the colonial war and the democratic revolution of 1974, and participated in the workers movements and citizens associations, that were part of the social background of the common lands devolution. They were aware of the social importance of baldios for the local populations, especially for those most in need. While at the time of devolution traditional uses had already been discontinued in the baldios, they had become an important source of revenues for local welfare, through the works of the parish and the local institutions for social care. Although the elected council has a management role, by law all the strategic decisions affecting the baldios are taken by the general commoner assemblies, where all commoners can vote regardless of their gender or socio-economic status. Thus, due to its democratic form of governance, baldios are an important place for experiencing democracy and experimenting with community-building. However, apart from forest workers and the associates from the social care institutions that benefit from the incomes, no one participates in these assemblies. Discussions on forest management are still considered too technical by the commoners and promptly relegated to the forest engineer.

In order for the forest to contribute to the wellbeing of future generations, it requires significant investments for its recovery from a poor system of defense from forest fires, massive invasive species (predominantly Acacia dealbata and Acacia melanoxylon), pine tree pests and diseases (notably pine wilt disease). The products of preventive silviculture and sanitation harvests, namely firewood and pine wood stands, were sold to partially fund new plantations and were also donated to local schools and institutions for space heating. However, the urgent needs of the current populations living with post-2008 austerity policies are more pressing each day. Due to the financial cuts of the governments to public spending for social support, and each euro that goes to the forest does not go to social welfare. Managers of common lands, once the provision for the poor and landless to cultivate rye, to make a living from charcoal, gathering brushes or herding sheep and goats [31], now face the moral obligation to provide welfare when the state fails to do so.

Although the commoners' regulation protects the traditional usufructary rights in the common lands, including mushroom picking, it was essential to promote new uses and devices for the commoners to meet the forest and its species. If the commoners fail to recognize these as common goods that must be recovered and managed sustainably, then the only value that will guide collective decisions is the short-term maximization of revenues.

The willingness of the local administrators to recover a forest for the well-being of the community attracted the interest of academics related to forestry and social sciences, who provided the community with their support as described in the methods section. The common land administrators were interested in mycological resources because some parcels were being intensively scavenged by non-local harvesters to feed the wild mushroom commercial circuit. Although they had traditional knowledge over a few edible species, primarily Macrolepiota procera, Tricholoma equestre 
and Tricholoma portentosum, now that they gained control over the forests the administrators aimed to have a fungal inventory of the area to include mushrooms in their forest plan. However, the academic researchers framed mushrooms in the larger framework of the full devolution of the common lands, which included the challenges of recovering not only the forest, but also the community. The forest engineer was deeply in line with this framework, perfectly aware that forest recovery can only take place if there is a wide support from community members. The local council was also acutely aware that community engagement was a key feature of an intergenerational project that was vital to the very social reproduction and defense of the common lands in the future. However the "wild harvest" of mushrooms for commercial purposes that motivated the first visit was disrupted, due to the clear-cut of sick pine trees infected with pine-nematode disease and other afflictions, to be replaced by a new plantation; however, mycological wandering and community building in the common lands had just begun.

\section{Re-Working Devices for Community Mycology}

The first visit to Vilarinho was a true mushroom hunt. Several members of the local council, including the president, were very excited to know which species were edible and find a good catch for a meal. Thus, the focus was on tuning the eyes to find hidden mushrooms and quickly explore the forests for mushroom "hot spots" to fill their baskets. However, when confronted with the biodiversity of species, it became progressively clear to them that an accurate identification takes time and requires the development of observation skills. We indeed found enough mushrooms to share a meal at the table, where they ate mushroom species of which they had no previous traditional knowledge, namely Lactarius delicious. This was a moment where the administrators began to "meet" the common lands resources and building trust among academics and commoners, reinforced by good digestions and the invitation for a 50-h mushroom training course held at the baldios headquarters, funded through the National Confederation of Agriculture training program.

The training course was given by the leading author of this paper which has an academic background in biology and is an amateur mycologist, and counted with the participation of other amateur mycologists of the Centre for Social Studies and members of mycological associations. The course was attended by the several members of the local council, the forest engineer, forest workers, curious commoners and urban dwellers. Some had never attended a training course before. The participants were a heterogeneous mixture, all sharing a true interest on wild mushrooms. The training approach was inspired by the ecologies of knowledge, where traditional and experience-based knowledge meet with professional and scientific knowledge to mutually enrich each other $[15,41]$. Thus, the locals were introduced by biologists and amateur mycologists from mycological associations to the biology, ecology and diversity of mushrooms, and they confronted this information with their own contextualized observations about the occurrence of the species-places of occurrence, seasonal dynamics and habitats. During the course, a visual catalogue of 44 mushrooms of the locality was elaborated with the help of amateur mycologists writing a field guide to the mushrooms in Portugal and the help of the participants. Each time we found contradictory information, this was further investigated, which lead to situated knowledge about species dynamics, such as the potential for a symbiotic relationship between Lactarius delicious with Arbutus unedo (strawberry tree), which was recently confirmed in vitro by a Portuguese research team [42], or unusual patterns of fructification regarding the influence of altitude on climate.

Knowledge about the edibility and toxicity of mushroom species was also approached in the same manner. We attempted to identify the edible species that had local names, some of which were very similar to toxic species (such as Ramaria flava, easily confused with other mildly poisonous species within the genus), thus requiring precaution. Gradually there was a shift to eat species more easily recognized with distinctive traits and more global information about its safety. This was a bumpy road, as some of the species recently described as toxic on field guides, namely Tricholoma equestre [43], are very well established in the regional habits of consumption. The processes that leads to accidental 
misidentifications and poisonings were also scrutinized by learning how the participants traditionally identify the species harvested, as some participants had cases of mushroom poisoning in the family or in friend's circles. This resulted in the final elaboration of rules for mushroom picking, ecological sustainability and safety.

The ecology of knowledge approach served as a basis for the collaboration protocol established a few months later, with the aim of co-producing knowledge relevant for the governance of the common lands. Although the course was a beginning where commoners and local administrators took the time to meet with diverse mushroom species, share knowledge, laughs and meals, it became clear that mycological activities had to be expanded to include: (1) commoners not directly related to the administration or forest work; and (2) a connection to the challenges of forest management, community governance and the socio-ecological narrative of the common lands. Thus, two devices were jointly elaborated and implemented in the scope of the protocol during the following years: Annual mycological walks and training courses.

\subsection{Mycological Walk}

The purposes of the walk were to: (1) provide an opportunity for the commoners to meet the territory, its species, management and governance; (2) introduce the walkers to the socio-ecological narrative of the common lands; and (3) provide an opportunity for students and researchers to visit the baldios of Vilarinho. Thus, although mycological walks had different objectives and target publics, they were open to everybody who was interested in participating. Care was taken to keep the walks deliberately open and avoid exclusions based on socio-economic status. The price was kept below five euros mostly to cover for logistic expenses concerning transportation for those who could not walk all the way, and for lunch. A difference in price was introduced between commoners and non-commoners to highlight the existence of people with differentiated rights and responsibilities (two euros for commoners, four euros for non-commoners, and no charge for children under 12).

The evolution of the number and kind of participants over the last five years was fairly positive. In the first two walks, there were 53 participants per year. In the second and third walk, 73 and 64 people participated, and in the last year the number increased to 135 . The participants compose a heterogeneous mixture of people who shared an interest in mushrooms and common lands: Mountain hikers, vegetarians, wilderness survival practitioners, activists engaged in environmentalist and radical democracy movements, neo-rurals, urban dwellers, Ph.D. students and social researchers, amateur photographers, school teachers, and middle-aged and elderly people interested in the collection of mushrooms, Arbutus unedo fruits, pine cones and chestnuts, among others. Men and women participated in equal proportion. The walk was intergenerational and a family activity, and people felt comfortable bringing their children and dogs. The number of children attending the walks was rising and, in the last year, one in six participants were under 12. It was also international, as up to one in seven participants were foreigners residing or visiting the region. The culture of inclusion and acceptance was present from the start, and the walk quickly turned into a communal space for conviviality.

The walk began by welcoming the participants and presenting the people who would guide them: The mycologist, the forest engineer and the president of the managing council. Along the way, some strategic stops were made where participants made a circle and the guides introduced a topic about the mushroom species, the habitat and territory. Lunch was offered to all, together with homemade liqueurs and roasted chestnuts typical of the St Martin feast [44]. At the end of the walk, the collected mushrooms were identified with the help of international field guides and information was provided about their edibility, toxicity and other uses.

The route was planned to be of medium-low difficulty, and was backed by Land Rovers to support those who could not go all the way. Almost all the route was in the common land territory, apart from the private lands at the beginning/end of the trail located at lowest altitudes. Walkers were not allowed to wander or collect mushrooms outside the established trail. 
Whenever possible, mushrooms along the way were used to introduce the socio-ecological narrative of the common lands. This was done through storytelling, starting by situating the mushroom species in popular culture and ecology, expanding their connections to the habitat and their ecological relationships and interdependences with trees and animals. Mushroom fruiting bodies are taken as an entry point to an invisible world of connections that must be in place for its emergence, which are critical for its sustainability and resurgence. The code for responsible and respectful harvest is explained through the biology of the species, its requirements for growth and reproduction and how can we collectively minimize damages to safely meet again next year.

By using the socio-ecological biography of mushrooms as an entry point, one could navigate on its complex ramifications into the situated biographies of the trees-how they arrived and radicated in the common lands territory. Thus, the forest and its species became historicized, no longer the result of a natural process without human intervention, but the active result of struggles for the control of the territory that materialized in different property regimes and ecosystems along the route: The communal usufruct, the state forest regime, the co-management, autonomous management and the current challenges. Then, the route becomes the physical expression of an ongoing tale that results in the degradation and improvement of the common lands. The narrative is developed along the way in the circle stops, and opens the way for all the guides to share their stories. It typically ends in a memorial for Frankelin, a commoner and firefighter that lost his life in the large fire of 2005, demonstrating the importance of forest management for the defense against fires and the respect for the commoners responsible for civil protection and the common lands preservation.

Participants can approach the guides along the way and during lunchtime for informal conversations to exchange more information about the topics of their interest. It is during these walks that new commoners unfamiliar with the baldios administration learn about their usufruct rights. Mushroom identification is the moment where the participants can fully contemplate the biodiversity of the species found, learn their names, edibility, toxicity and potential uses. It is also when field guides are used and compared, and additional information and resources are exchanged.

The structure of the mycological walks was re-worked through the years. The variable elements were the route and the lunch. Initially, the route leaded to the heart of the common lands, the Hazel Park in the middle of the old-growth forest. This is a leisure park in an area of prized beauty built by the local administrators where participants could enjoy the sight of some centenary-old chestnuts planted by the commoners, the oldest Pseudotsuga menienzii planted by the forest services and diverse broadleaf trees. This park is underused by the commoners who typically do not go up the mountain. However, this route had a medium level of difficulty and was more suited to mountain hikers. Thus, the difficulty of the trail was lowered by re-routing to areas of lower altitude to avoid excluding people, especially the elderly commoners and the children, due to the harshness of the terrain. Lunch variations concerned the food and the place served. Initially it was served in the Hazel Park, which involved a considerable logistic effort. This prevented some local council members, their wives and the workers (there are only two women with administration roles and two women workers on the common lands) from participating in the walk, by them having to focus on preparing and transporting the meal. Typically, large meals were offered as is traditional in the region, consisting of soup and a meat dish. However, this excluded the vegetarians from eating, and was replaced by two pots of rice with mushrooms, one with meat and another without. By re-routing, lunch was served in a park built by the parish administration and later on, with the increase in the number of participants, was served in the facilities of the recreational club of Vilarinho. The weather was also an unpredictable variable which lead to some adjustments to provide shelter for the walkers, especially during lunch, but the walk itself was not conditioned by climate variables once scheduled. Unless there were safety warnings given by the civil protection authorities, the walk was done in rain or shine. In addition, the presence of wild mushrooms is erratic, and while in some years they were so abundant that we could grill them and serve them to the walkers on the parks, in one year they were practically absent, apart from a dozen 
species that can be found yearlong. Thus, the meals are usually prepared with cultivated mushrooms bought in stores.

In the first three years, non-commoners outnumbered the commoners in a proportion of two to one, but in the last two years the proportion increased to three to one. Non-commoners that identified with communitarian ways of organization aimed to support the baldios efforts to recover the forest and the community of commoners. A core nucleus attended each year and brought their family and friends. A network of supporters started to emerge and helped to give visibility to the ongoing work, namely through news in the media. The walk also allowed the local council to recruit new commoners previously unaware of their usufruct rights and responsibilities. One in particular was invited to the General Assembly Board and accepted the invitation. The hike was also an opportunity to meet professors, researchers and students interested in the topic who were working in other places of the country.

During the first years, the presence of the elderly commoners was disappointing. However, their numbers are increasing. Their presence lead to some re-workings, namely the public recognition of the names of the commoners engaged in the organization, and the manifestation of feelings of community and common identity. Invariably, the walk ended with farewells and the same greeting from participants: See you next year!

\subsection{Training Courses}

Drawing from previous experiences, the course was re-worked and implemented in close collaboration with the forest engineer to move from a mushroom-centered approach to a mushroom-in-baldios approach. The course was announced together with the mycological walk and occurred in the same month. We easily managed to recruit participants previously unrelated to the baldios administration, both commoners and non-commoners, while members of the local council were regular participants. The course was presented after working hours in the baldios headquarters. The syllabus started with an introduction to the biology and ecology of fungi and mushrooms, explaining their cellular organization in hyphae-filamentous structures that branch and grow radially, collectively composing the mycelium. This biological network is not capable of producing its own food, and according to the species and ecological circumstances, feeds by decomposing dead matter, establishing mutual associations with plant roots (mycorrhiza), cyanobacteria and algae (lichens), or parasitizing plants, other fungi or animals, including humans (mycoses, which are fungal infections). We presented mushrooms as "the tip of the iceberg", erratic fruiting bodies from invisible mycelia that exist yearlong in the soil, and which are essential to the existence of forests. After presenting our most common mushroom species, we take the case of mycorrhizal edible mushrooms and follow their mycelial connections to the trees to expand the theme into forest management. Then, the forest engineer presents practical exercises taken from situations actually taking place in the common lands, such as the reforestation of forest areas damaged by the pine nematode disease, to calculate the possible costs and benefits of using trees inoculated with edible fungi intended to increase the production of wild mushrooms for commercialization in the future. The socio-ecological dilemmas regarding this technology are further expanded into forest governance, by collectively inquiring into the implications of favoring particular wild mushroom species for market purposes. Some of the issues raised were: Who would be excluded from common usufructary rights, who would profit from the commercialization of mushrooms, how to ensure a fair distribution of the benefits and the costs of monitoring the resource to prevent poaching, among others.

At the end of the course, the trainers openly discussed with the participants the experimental approach taken to expand the syllabus and asked for their critical evaluation. Some participants, for example, expressed the feeling of being "caught" by mushrooms and drawn into topics that would not have attracted their attention in the first place or might even have caused them adverse reactions, such as discussions about governance and politics; but they seemed to value the experience very 
positively. The group also expressed the wish to meet again and continues to be engaged in activities related to mushrooms and the common lands.

\section{Discussion}

In the previous sections, we presented the setting for the mushroom enclosure that is taking place in Portugal, which is trying to restrict mushroom harvest by mushroomers. This restriction is backed by law, which considers mushrooms as property of the landowners. Thus, we set to inquire into the possible role that common lands may have to keep some spaces open to mycological practices traditionally carried out by local populations and further expanded by amateur associations within a naturalistic spirit. Such activity implies the preservation of spaces for the collection of mushrooms without commercial purposes of any sort, either be the sale of fruiting bodies or the creation of touristic mushroom hunting areas. Thus, the mushroomer is not framed as a tourist that consumes a set of experiences previously packaged and made available to them, but as a wanderer who can engage in responsible and respectful relations with the people and the places they meet. However, local administrators cannot allow unregulated access to the common lands without facing the risk of endangering the sustainability of these common resources. As commoners that experienced dispossession, they are acutely aware that the current context favors cooperation for profit-seeking over the provision of common goods. Thus, encounters between commoners and mushroomers "in the wild" require precautionary measures, while keeping an open space for respectful engagements.

The mycological walk is a device that provides an opportunity for non-pressurized forms of cooperation [41]. Allowing informal conversations along the way, outside of the storytelling circles, creates an opportunity for face-to-face interactions to occur between the participants and with the local administrators, where no one is forced to give all the details at once. Thus, while it is a tool for conviviality, the walks are also a place where persons can mark and observe at a distance the behavior of each other, to become acquainted and get to know each other while mutually testing, challenging and daring before making any further commitments or alliances. In this sense, the walk establishes a relationship of commensalism, where local administrators are the hosts and the walkers are the commensals, benefiting from the hosts without causing them harm.

The walk structure necessarily implies a limitation in the movements of the mushroomers, which, although they may explore the route at their own pace, must stick to the trail that was previously established. Given the heterogeneity of the participants, this causes a constant tension for those that aim to explore freely the territory in search for the best mushroom hot spots or landscapes. Simultaneously, this loss of freedom of movement defines a common space for people that otherwise rarely meet, such as the home-schooled children of the foreign neo-rurals and the local children educated in public schools, or the environmentalist-vegetarians with the hunter-commoners.

The expansion from a mushroom-centered approach to a mushroom-in-baldios approach results in a kind of snare where participants fall "down the rabbit hole" into a socio-ecological web of relations they would probably not have anticipated or met otherwise. This opened a space for the participants to respond to more than mushrooms, and cultivated their abilities to respond to each other as well. This web of relations must provide for the resources that otherwise would be gathered elsewhere. Otherwise, it is no longer possible to stick together and the web dissociates. A good example is the meal: Wild mushrooms cannot provide food to all the participants because their abundance is unpredictable in time and place. One year, Lepista nuda (blewits) were present in the Hazel Park and were enough to feed all the vegetarians and be tasted by all the participants. This experience was in the memory of all, as well as the chestnuts that were collectively picked during the walk and then roasted and enjoyed together. However, as the walk does not respond to mushrooms abundance alone, but to a communing experience in a territory, the provision of goods must be secured from other sources, including through commercial sources.

The responsibility to secure the provision of goods is disproportionate among the participants, as it falls primarily upon the local administrators and organizers of the walk. However, what is 
interesting is the constant tension created by participants that would like to reduce this distance by contributing more to the organization of the event. Suggestions such as organizing a potluck meal, using food locally grown, washing their own dishes or paying a higher fee were expressed voluntarily by some. However, like wild mushrooms, these contributions are erratic, given freely and unless they become institutionalized, are not enough to secure the organizational tasks needed to ensure the success of the event. Nevertheless, there is resistance to the idea of delegating the meal into a restaurant or professional catering service precisely for reducing the administrators' duties as hosts.

There are several aspects that distinguish this mycological walk from others, its most distinctive trait being the connection to the territory and the process of community building. Mycological walks that are mushroom-centered are focused on the catch-the abundance and diversity of mushrooms found, the identification of the species and their nutritional properties, gastronomic value and market price as well as their potential for use and commercialization. Typically, these kinds of walks involve professional chefs or local restaurants, lectures by scientists or keynote speakers, and show cooking. Thus, mushrooms are framed as a resource ready to be removed from places to generate revenues for those involved in the commercial circuit. However, when the connection to the territory and ownership is lost, this may result in conflicts with local landowners that are not involved in the circuits and see their properties scavenged.

Although mushroom-centered activities are still there, the expansion into mushroom-in-baldios spreads its mycelia deep into the territory bringing other topics to the surface. The interference between the mushroomer way and the commoner way to establish people-forest connections results in a paradox. Mushroom wanderers value the freedom to roam, to move without limitations in unenclosed lands, and to find unanticipated wonders. However, in Portugal, the last stewards of open spaces may be local communities that accept the responsibility of governing them and keeping them open to wild mushroom gathering as an extension of the original ethos of the common lands. Conversely, commoners need the support and engagement of mushroomers to justify their efforts of recovering forests for the purpose of gathering wild mushrooms for recreation, opening up the community to responsible wanderers.

The promotion of responsible mushroom wandering also provides an opportunity for biology and social sciences to engage with each other, training professional and amateur mycologists in the field of academic-society relationships. This is more in line with the approach of radical mycology, a grassroots movement and social philosophy that respectfully uses the lifecycles of fungi and their ecological relationships as tools for humans to learn how best relate to each other and steward the world they live in [14]. By situating mushrooms in relation to community and societal challenges, training people in mycology becomes a tool to educate people for social responsibility [45] and the syllabus changes [46].

While outsiders are increasingly participating in the mycological walks with their families, commoners are not increasing in the same proportion. The mushroom activities are definitively a place for many city commoners to learn about their rights for the first time and for the local administrators to invite them to participate in the governance of the common lands. However, the reasons why these devices are failing to engage other commoners will be investigated in a near future, to develop different devices for them to value, experience and practice community forestry.

Mycotourism programs may also offer solutions to provide leisure for mushroomers and reduce the conflict with landowners. However, their solution is commercial, proposing to give a share of the revenues to landowners as in some regions of Spain [9], conditioning wild mushroom picking through payment. Devices and policies will have to be worked out locally to implement mycotourism programs, allowing for the long-term engagement of mushroomers in community projects that aim to recover the forests where wild mushrooms flourish.

The governance of mushrooms in the common lands of Vilarinho is an open question. It is not clear if the community will be able to resist the constant temptation of enclosing mushrooms. The outcome will depend on the response of mushrooms, mycologists, local administrators, commoners 
and poachers, operating within an existing legal and economic framework that favors the eradication of resources, rather than a framework that considers the long-term relationships that sustain places.

Acknowledgments: The authors gratefully acknowledge the financial support of the project "SCRAM-Crises, risk management and new socio-ecological arrangements for forests: A perspective from science and technology studies", co-funded by COMPETE (Operational Competitiveness Program) (FEDER) and the Portuguese Foundation for Science and Technology (FCT) (PTDC/CS-ECS/102041/2008; FCOMP-01-0124-FEDER-009236). We are profoundly grateful to Rick Kool for the English revision and all the valuable comments and suggestions. Special thanks go to the commoners of Vilarinho, Lousã for their invaluable support in all the activities developed.

Author Contributions: All authors participated in the design of the pilot project, analyzed and interpreted the data. Rita Serra and Eugénia Rodrigues performed the activities described. Rita Serra wrote the paper.

Conflicts of Interest: The authors declare no conflict of interest.

\section{References}

1. Stamets, P. Mycelium Running: How Mushrooms Can Help Save the World; Ten Speed Press: Berkeley, CA, USA, 2005.

2. Fine, G.A. Morel Tales: The Culture of Mushrooming; Harvard University Press: Cambridge, MA, USA, 1998.

3. Donoghue, E.M.; Sturtevant, V.E. Forest Community Connections: Implications for Research, Management, and Governance; RFF Press: Washington, DC, USA, 2008.

4. Serra, R.; Ferreira, P.; Skulska, I.; Alavez-Vargas, M.; Salgado, A.; Nunes, J.A.; García-Barrios, R. Education for Sustainability in the Context of Community Forestry. In Biodiversity and Education for Sustainable Development; Castro, P., Azeiteiro, U.M., Bacelar-Nicolau, P., Leal Filho, W., Azul, A.M., Eds.; Springer: Berlin, Germany, 2016; pp. 169-183.

5. Tsing, A.L. The Mushroom at the End of the World: On the Possibility of Life in Capitalist Ruins; Princeton University Press: Princeton, NJ, USA, 2015.

6. Robbins, P.; Emery, M.; Rice, J.L. Gathering in Thoreau's backyard: Nontimber forest product harvesting as practice. Area 2008, 40, 265-277. [CrossRef]

7. Bullock, R.C.L.; Hanna, K.S. Community access and the culture of stewardship in Finland and Sweden. In Community Forestry: Local Values, Conflict and Forest Governance; Bullock, R.C.L., Hanna, K.S., Eds.; Cambridge University Press: New York, NY, USA, 2012; pp. 147-172.

8. Staddon, C. Towards a critical political ecology of human-forest interactions: Collecting herbs and mushrooms in a Bulgarian locality. Trans. Inst. Br. Geogr. 2009, 34, 161-176. [CrossRef]

9. De Frutos, P.; Martinez-Peña, F.; Aldea, J.; Campos, P. A Model to Estimate Willingness to Pay for Harvest Permits for Wild Edible Mushrooms: Application to Andalusian Forests. Forests 2016, 7, 292. [CrossRef]

10. Bullock, R.C.L.; Hanna, K.S. Community Forestry: Local Values, Conflict and Forest Governance; Cambridge University Press: New York, NY, USA, 2012.

11. Flint, C.G.; Luloff, A.E.; Finley, J.C. Where is "community" in community-based forestry? Soc. Nat. Resour. 2008, 21, 526-537. [CrossRef]

12. McLain, R.; Jones, E. Challenging 'Community' Definitions in Sustainable Natural Resource Management: The Case of Wild Mushroom Harvesting in the USA; IIED Sustainable Agriculture and Rural Livelyhoods Programme; IIED: London, UK, 1997. Available online: http:/ / pubs.iied.org/pdfs/6130IIED.pdf (accessed on 24 March 2017).

13. Copena Rodríguez, D.; Simón Fernández, X.; Pérez Neira, D. O aproveitamento do recurso micológico como oportunidade de desenvolvimento rural nos montes veciñais de Galiza. In Construíndo Coñecemento Agroecolóxico. Cambiando os Modelos de Consumo Para Construír Sistemas Agroalimentarios Sustentables; Simón Fernández, X., Copena Rodríguez, D., Pérez Neira, D., Eds.; Grupo de Investigación en Economía Ecolóxica, Agroecoloxía e Historia: Vigo, Spain, 2016; pp. 204-215. Available online: http:/ / economiaecoloxica.webs.uvigo.es/docs/publicacions/capitulo_aproveitamentos_micoloxicos_ montes_vecinais_2016.pdf (accessed on 24 March 2017).

14. McCoy, P. Radical Mycology: A Treatise on Seeing and Working with Fungi; Chthaeus Press: Portland, OR, USA, 2016.

15. García-Barrios, R.; Alavez-Vargas, M.; Skulska, I. La Forestería Comunitaria: Un espacio privilegiado para otra ecología de poderes y saberes. In SCRAM—Crises, Gestão de Risco e Novos Arranjos Sócio-Ecológicos Para 
Florestas: Uma Perspetiva Dos Estudos Sobre Ciência e Tecnologia; Final Report; CES Publications: Coimbra, Portugal, 2013; pp. 29-110. Available online: http://ces.uc.pt/temp/scram/SCRAM_RelatorioFinal.pdf (accessed on 24 March 2017).

16. Wynne, B. May the Sheep Safely Graze? A Reflexive View of the Expert-Lay Knowledge Divide. In Risk Environment and Modernity: Towards an New Ecology; Lash, S., Bronislaw, S., Wynne, B., Eds.; SAGE: London, UK, 1996; pp. 44-83.

17. Elinor, O. Governing the Commons: The Evolution of Institutions for Collective Action; Cambrige University Press: Cambridge, UK, 1990.

18. García-Barrios, R.; Serra, R. Reflexiones sobre la cooperación humana y los derechos em la era de las crisis. In Universidad Pública, Organización Comunitária y Ambiente: Once Estudios de Desarollo Alternativo en México; Chávez-Jiménez, D., Núñez-Madrazo, M.C., Rodríguez-Soto, C., Eds.; Universidad Autónoma del Estado de México: Toluca, México, 2016; pp. 97-118.

19. Statistical Office of the European Union (EUROSTAT). Agriculture, Forestry and Fishery Statistics; Publications Office of the European Union: Luxemburg, 2016. Available online: http:/ /ec.europa.eu/eurostat/en/web/ products-statistical-books/-/KS-FK-16--001 (accessed on 24 March 2017).

20. Food and Agriculture Organization (FAO). Global Forest Resources Assessment; FAO: Rome, Italy, 2015. Available online: http:/ / www.fao.org/3/a-i4808e.pdf (accessed on 24 March 2017).

21. Mendes, A.M.C. Implementation analysis of forest programmes: Some theoretical notes and an example. For. Policy Econ. 2006, 8, 512-528. [CrossRef]

22. Feliciano, D.; Alves, R.; Carvalho Mendes, A.; Ribeiro, M.; Sottomayor, M. Forest Land Ownership Change in Portugal; COST Action FP1201 FACESMAP Country Report; European Forest Institute Central-East and South-East European Regional Office (EFICEEC-EFISEE) and University of Natural Resources and Life Sciences: Vienna, Austria, 2015. Available online: http://facesmap.boku.ac.at/library/countryreports (accessed on 24 March 2017).

23. Presidency of the Portuguese Council of Ministers. Estratégia nacional para as florestas. Diário Repúb. 2015. Available online: https:/ / dre.pt/application/file/66432612 (accessed on 24 March 2017).

24. Reboredo, F.; Pais, J. Evolution of forest cover in Portugal: From the Miocene to the present. In Forest Context and Policies in Portugal; Reboredo, F., Ed.; Springer: Berlin, Germany, 2014; pp. 1-37.

25. National Commission for the Valorization of Communal Territories (CNVTC). Programa Nacional Para a Valorização dos Territórios Comunitários; Portuguese Ministry of Agriculture, Rural Development and Fisheries and National Forest Authority: Lisbon, Portugal, 2010.

26. Portuguese Institute for the Conservation of Nature and Forests (ICNF). IFN6-Áreas Dos Usos Do Solo e Das Espécies Florestais de Portugal Continental. Resultados Preliminares; Instituto da Conservação da Natureza e das Florestas: Lisboa, Portugal, 2013. Available online: http:/ /www.icnf.pt/portal/florestas/ifn/resource/ ficheiros/ifn/ifn6-res-prelimv1--1 (accessed on 24 March 2017).

27. Pinto-Correia, T.; Ribeiro, N.; Sá-Sousa, P. Introducing the montado, the cork and holm oak agroforestry system of Southern Portugal. Agrofor. Syst. 2011, 82, 99-104. [CrossRef]

28. Nunes, J.A.; Feijó, R. As transformações dos incultos no Noroeste (1750-1900): Uma proposta de reapreciação. Cad. Ciênc. Soc. 1990, 8-9, 45-90.

29. Brouwer, R. Planting Power: The Afforestation of the Commons and State Formation in Portugal; Eburon: Delft, The Netherlands, 1995.

30. Brouwer, R. Between Policy and Politics: The Forestry Services and the Commons in Portugal. For. Conserv. Hist. 1993, 37, 160-168. [CrossRef]

31. Monteiro, P.F. Terra Que já foi Terra: Análise Sociológica de Nove Lugares Agro-Pastoris da Serra da Lousãa Edições Salamandra: Lisboa, Portugal, 1985.

32. Valente, S.; Coelho, C.; Ribeiro, C.; Liniger, H.; Schwilch, G.; Figueiredo, E.; Bachmann, F. How much management is enough? Stakeholder views on forest management in fire-prone areas in central Portugal. For. Policy Econ. 2015, 53, 1-11. [CrossRef]

33. Canadas, M.J.; Novais, A. Bringing local socioeconomic context to the analysis of forest owners' management. Land Use Policy 2014, 41, 397-407. [CrossRef]

34. Miranda, M.G.C. Desenvolvimento de um Projecto de Educação Ambiental na Área da Micologia. Master's Thesis, University of Trás-os-Montes and Alto Douro, Vila Real, Portugal, 2012. Available online: https:/ /repositorio.utad.pt/bitstream/10348/2479/1/MsC_mgcmiranda.pdf (accessed on 24 March 2017). 
35. Mendes, A.M.C. Forest Owners' Organizations in Portugal: Are the infant going to survive? In Proceedings of the IUFRO 3.08 Conference on Small-Scale Forestry and Rural Development-The Intersection of Ecosystems, Economics and Society, Galway, Ireland, 18-23 June 2006. Available online: http://www.coford.ie/ media/coford/content/publications/projectreports/small-scaleforestryconference/Mendes.pdf (accessed on 24 March 2017).

36. Serra, R.; Alavez-Vargas, M. Collaborative production of knowledge about forest governance in Portugal. In Proceedings of the IX Jornadas Latinoamericanas de Estudios Sociales de la Ciencia y la Tecnología, UNAM, Mexico City, Mexico, 5-8 June 2012.

37. Viegas, D.X.; Ribeiro, L.M.; Viegas, M.T.; Pita, L.P.; Rossa, C. Impacts of fire on society: Extreme fire propagation issues. In Earth Observation of Wildland Fires in Mediterranean Ecosystems; Chuvieco, E., Ed.; Springer: Heidelberg, Germany, 2009; pp. 97-109.

38. Tavares, A.O.; Monteiro, M.; Vargas, M.A.; Pato, R.L.; Serra, R. Land use change and forest routing in a rural context: The relevance of the community-based management and planning framework. Appl. Geogr. 2014, 52, 153-171. [CrossRef]

39. Serra, R.; Ferreira, P. Governação Comunitária de Florestas Para Crianças: Kit Pedagógico; CES Publications: Coimbra, Portugal, 2017. Available online: http://ces.uc.pt/temp/scram/KitPedagogicoSCRAM.pdf (accessed on 24 March 2017).

40. Baldios dos Lugares da Extinta Freguesia de Vilarinho, Lousã. Available online: http:/ /www.baldiosvilarinholsa.pt (accessed on 24 March 2017).

41. Santos, B.S. A ecologia de saberes. In A Gramática do Tempo: Para Uma Nova Cultura Política; Santos, B.S., Ed.; Afrontamento: Porto, Portugal, 2006; pp. 127-153.

42. Gomes, F.; Suárez, D.; Santos, R.; Silva, M.; Gaspar, D.; Machado, H. Mycorrhizal synthesis between Lactarius deliciosus and Arbutus unedo L. Mycorrhiza 2016, 26, 177-188. [CrossRef]

43. Roux, P.; Eyssartier, G. Le Guide Des Champignons, France et Europe; Belin: Paris, France, 2011.

44. I Caminhada Micológica No Baldio de Vilarinho 2012. Available online: https://www.youtube.com/watch? v=WK9waBzQYWE\&t (accessed on 24 March 2017).

45. Gilbert, S.F.; Fausto-Sterling, A. Educating for social responsibility: Changing the syllabus of developmental biology. Int. J. Dev. Biol. 2003, 47, 237-244.

46. Fausto-Sterling, A. Science matters, culture matters. Perspect. Biol. Med. 2003, 46, 109-124. [CrossRef] [PubMed] 